\title{
DESIGN AND PERFORMANCE EVALUATION OF A DUAL-OPERATION CONDENSER USING R-134A
}

\author{
NWASUKA N. C..$^{*}$, NWAIWU U. ${ }^{2}$, NWADINOBI C. P. ${ }^{3}$, CHIDEBE C. E. ${ }^{4} \boldsymbol{\&}$ IKEH V. C. ${ }^{5}$ \\ ${ }^{1,2,3}$ Department of Mechanical Engineering, Abia State University, Uturu, Nigeria. \\ ${ }^{4}$ Refrigeration and Air-Conditioning Department, Skill G Innovation Centre, Abuja. \\ ${ }^{5}$ Department of Mechanical Engineering, Nigerian Defence Academy Kaduna.
}

\begin{abstract}
This research considered the design and performance evaluation of a condenser using R134a refrigerant for use in refrigeration and air-conditioning. The optimal values were obtained by varying different performance parameters. Experiments were conducted in order to justify the performance of the condensers, if it will perform better with a more eco-friendly refrigerant. The simulated Ansys results showed that R134a suits refrigeration and air-conditioning system. More so, Copper offered better platform for heat transfer more than aluminum. But the limitation observed in the use of Copper is its weight, thus aluminum alloy 1100 can be an alternative. Heat transfer analysis was done on the condenser to evaluate the material and refrigerant. The materials considered for tubes are Copper and Aluminum alloy 1100 and for fins are 1050 and 1100.

KEYWORDS: Condenser, R 134a, Performance evaluation, COP, Ansys, Copper
\end{abstract}

Received: Jun 10, 2020; Accepted: Jun 30, 2020; Published: Aug 04, 2020; Paper Id.: IJMPERDJUN2020612

\section{INTRODUCTION}

Optimizing a refrigeration and air-conditioning system presents a complex problem for many industrial reasons. To start, there are many parameters that could be varied for each component. The effect of varying most parameters is not independent on a component or system basis. Even if a component is optimized for specific operating conditions, like inlet and outlet conditions, it is necessary to optimize each component at its unique operating conditions with all other system components. To get a fair comparison among different designs, operating conditions such as air velocity and refrigerant charge, need be optimized for each design. However, optimizing these parameters will affect the cooling capacity of the evaporator, skewing the comparison (Sadler, 2000). Because of damaging effect of CFC refrigerants on stratospheric ozone layer, international agreement (Montreal Protocal) has been signed by many countries to curtailing the use of CFCs on a global scale. Here, an attempt is made to design condenser for refrigeration and air-conditioning purposes using ecofriendly refrigerant pair R134a. These refrigerants have zero ozone depletion potential and minimum global warming potential. Therefore, it is paramount to note that the best and effective way to design a condensers would be to keep the sizes of the condenser as small as possible and with special heat transfer enhancement mechanisms. For this, it is imperative to also know the flow condensation heat transfer coefficients (HTCs) of refrigerants. To investigate the overall performance of the condenser, heat transfer behaviors for refrigerant side as well as water side must be considered simultaneously (Parekh, and Tailor, 2013).

Condensers can be divided into two types:

- $\quad$ Air-cooled condensers. 
- Water-cooled condensers.

\subsection{Air-cooled condensers}

These condensers are divided according to their heat transfer characteristic:

a) Condensers with natural convection.

b) Condensers with forced convection.

\section{a) Condensers with natural convection:}

In these condensers, the heat discharging from the cooling material to the surrounding air is done through the pipe's side to its surrounding air without any external factor. The air warms up due to heat absorption, rises, and clear off space for cooler surrounding air. This process is a natural one caused by the air difference in temperature. The air rises up and is mixed with the surrounding air, and cooler air reaches the condenser's pipe surrounding in order to absorb more heat.

\section{Surface condenser:}

The surface condenser is aimed for small devices, mainly for domestic refrigerators. The simplest surface condenser is built from a copper pipe, bent and strengthened with iron wires. The main function of the iron wires in this type of condenser is to distribute the heat from the pipes to the air.

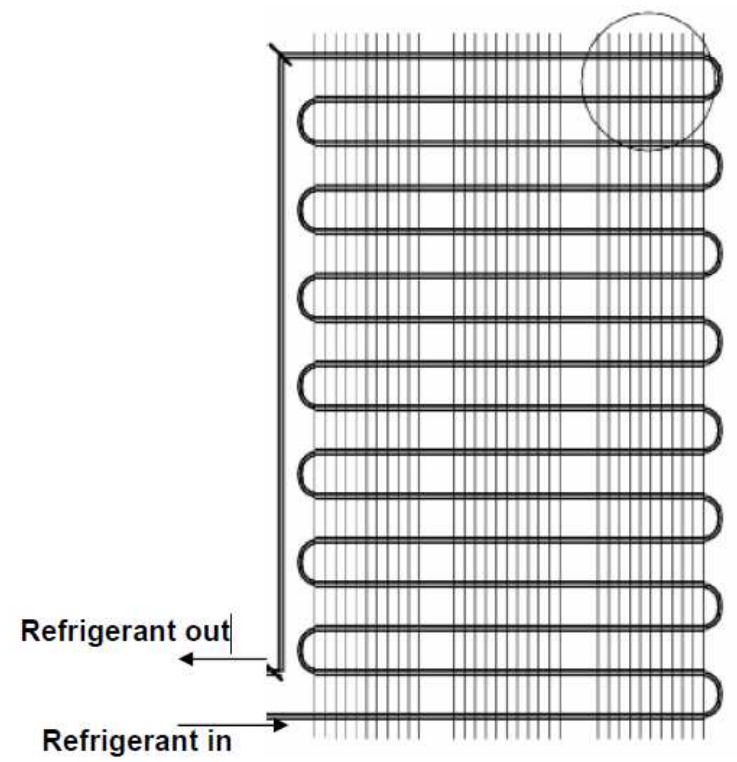

Figure 1: Schematic of a wire-and-tube type condenser (Parikshitet al, 2016)

Another type of surface condenser is a condenser made of an iron surface, which includes the pipe where the cooling material is flowing. The iron surface is used to improve heat transfer by enlarging the condenser's surface, thus the number of pipes needed for one condenser can be reduced. This condenser is also aimed for domestic refrigerators. In these refrigerators, the surface condenser is sometimes latent from sight, but always situated in free air. 


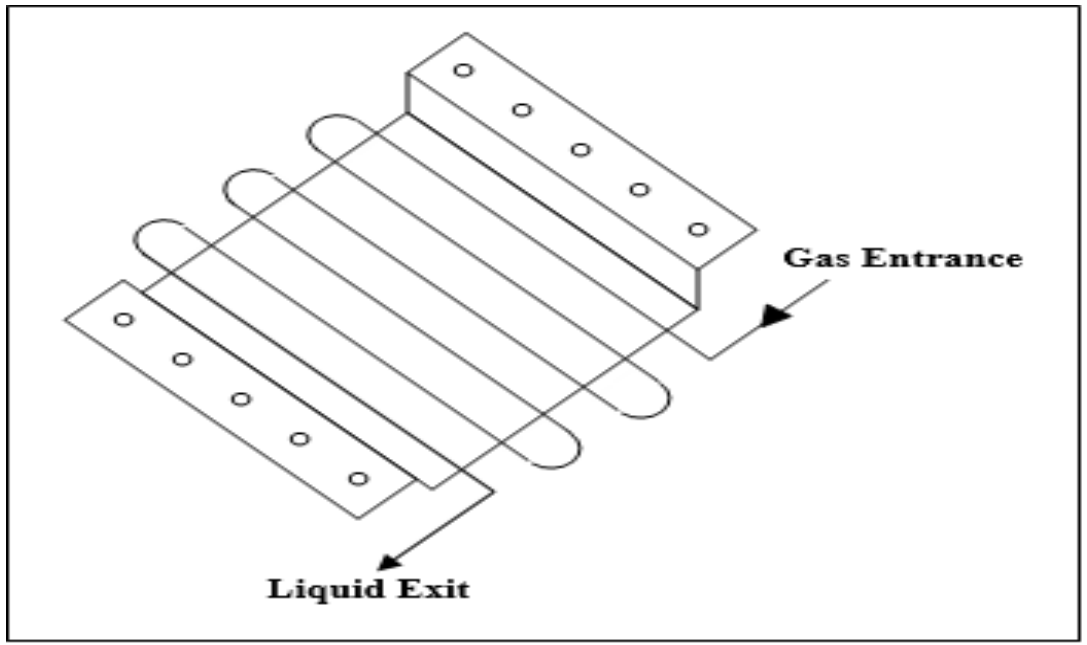

Figure 2: Surface condenser

In many cases, the cooling material is used to cool down the compressor's oil. The compressor's pipe leaving the compressor, enters the condenser, cools down, and returns to the oil in order to cool it down. Another way of cooling the oil crankcase is connecting the pipe (in the oil crankcase) to the condenser itself.

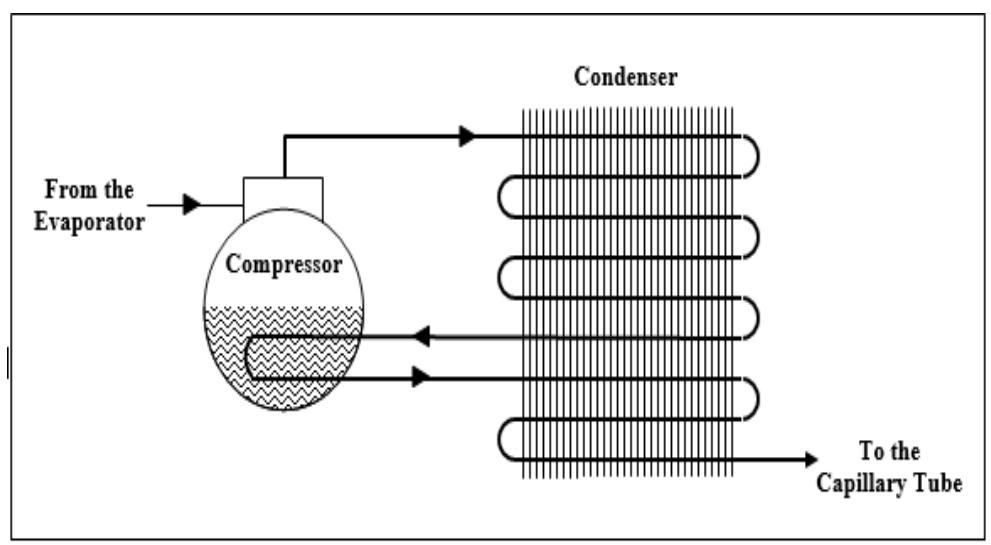

Figure 3: Flow of refrigerant in the tubes

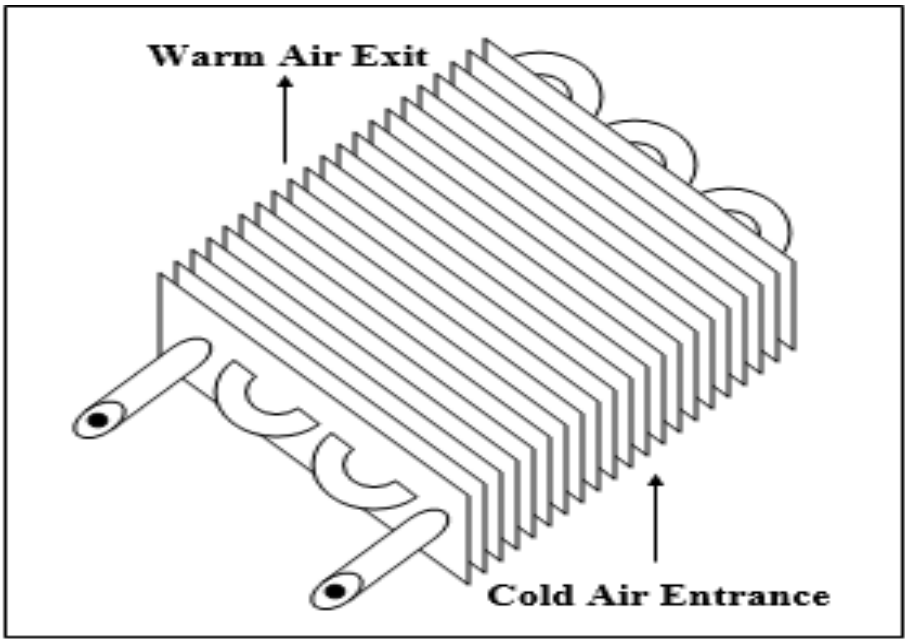

Figure 4: Condensers with forced convection 


\subsection{Condensers with forced convection:}

This condenser includes copper piping and aluminum sides. The sides' function is to enlarge the condenser's surface area, thus the passage of heat through it is larger, as described in the following figure 3 :

The forced convection condenser includes a polygonal condenser and a blower, which causes the air to flow through the polygonal condenser. The blower can be axial or centrifugal, but in most cases, it is axial. The blower forces the air to pass through the condenser's battery and to absorb the heat coming from the condenser.

\subsection{Circular condenser:}

The condenser is designed in a circular way for certain air-condition devices. The air enters from the sides and the axial blower pushes it up. Because of its special design, the circular condenser is more expensive than the regular condenser.

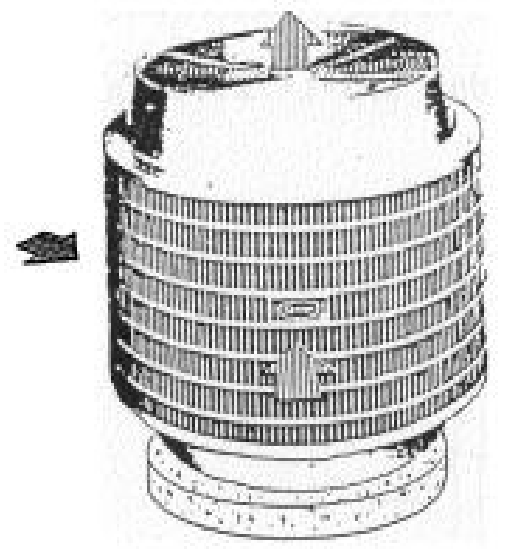

Figure 5: Axial Condenser

The Air-cooled condenser of large cooling and air-conditioning systems is a single unit including: condensing battery, air blower, and a motor which operates the blower in direct ignition when the blower is installed on the motor's axle, or by flywheel using straps.

Vertical condensers occupy small floor space, but they are sticking out. The air flows through them horizontally. Horizontal condensers occupy big floor space, but do not stick out. The air flows through them vertically

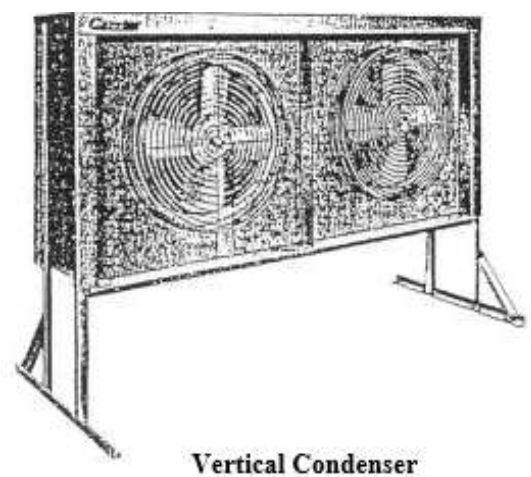

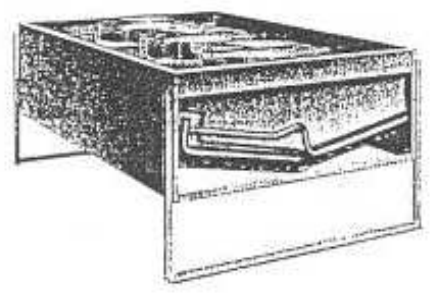

Horizontal condenser

Figure 6: The Air-cooled condenser

\subsection{Shell-and-tube type:}

This type of condenser offers a 2 tonnage to thousands of tonnage capacities, the refrigerant flows through the shell while water flows through the tubes in single to four passes. The condensed refrigerant settles at the bottom of the shell. The coldest water contacts the liquid refrigerant so that some subcooling can also be obtained. The liquid refrigerant is drained 
from the bottom to the receiver. There is a vent connecting the receiver to the condenser in other to ensure smooth drainage of liquid refrigerant. The shell also acts as a receiver. Furthermore, the refrigerant also rejects heat to the surroundings from the shell. The most common type is horizontal shell type. A schematic diagram of horizontal shell-and-tube type condenser is shown in Fig. 7. Vertical shell-and-tube type condensers are usually used with ammonia in large capacity systems so that cleaning of the tubes is possible from top while the plant is running.

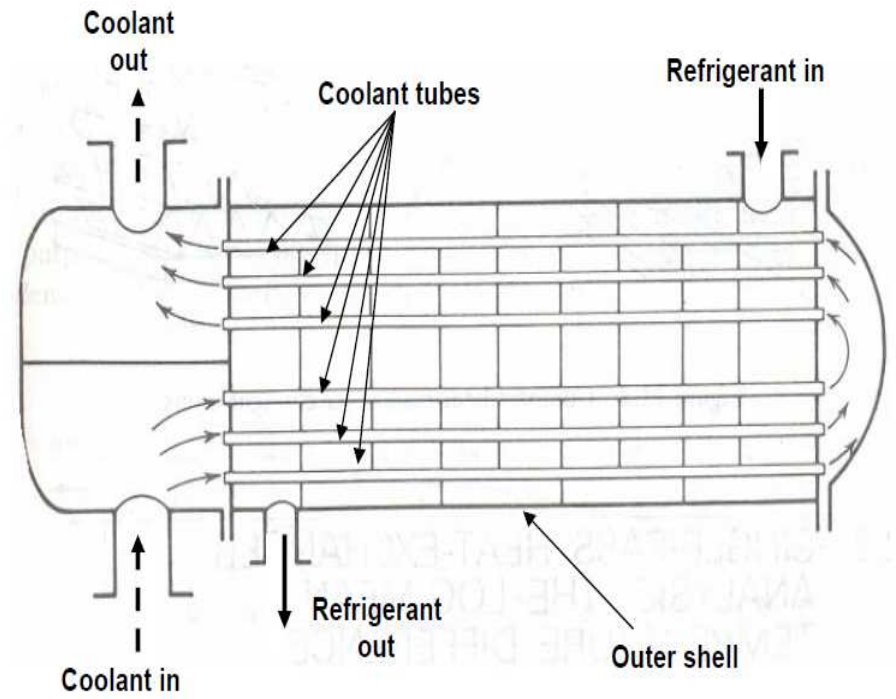

Figure 7: A two-pass, shell-and-tube type condenser (Yusuf, 2014)

Furthermore, Anil et al (2016) stated that the extraction of heat from lower temperature to higher temperature will be achieved by use of refrigeration. Heat is transferred from the process fluid (steam) to the cooling medium (air) through the fin tube bundle. According to Ali and Ali (2015), vapour compression machine is made up of components like compressor, condenser, expansion valve and evaporator. The machine expunges heat by evaporation. Majority of the refrigerators works on the Vapor compression refrigeration system. The performance of the system depends on the performance of all the components of the system (Hussainet al, 2016). Condenser is an important component in a power plant where the latent heat of the turbine exhaust steam is transferred to cooling medium which is eventually dissipated to the atmosphere. This waste heat limits the thermal efficiency of modern steam power plants to $40 \%$. The condenser is designed to maintain an economical condenser pressure determined by the cooling medium temperature. The work done in the turbine varies depending on the turbine back pressure which in turn depends on the temperature of the cooling medium. Fig.8 shows the Rankine cycle on T-S diagram (Murti, 2015).

Ts Diagram

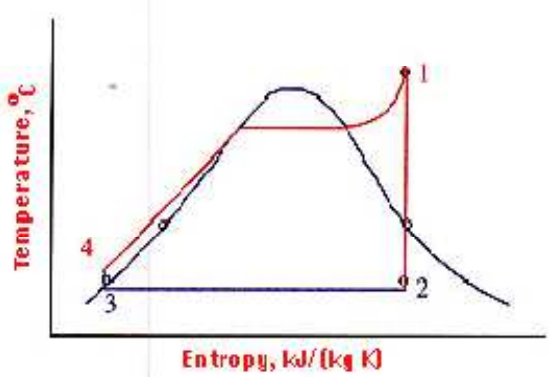

Figure 8: T-S diagram (Murti, 2015) 
The design of condenser plays a very important role in the performance of a vapor compression refrigeration system. Effective new designs are possible through theoretical calculations, however may fail due to the reason that the uncertainties in the formulation of heat transfer from the refrigerant inside the condenser tubes to the ambient air.

According to Venkatesh and Kishore (2017); Parekh, and Tailor (2013) the best way to design effective condensers would be to keep the size as small as possible with special heat transfer enhancement mechanisms. For this, it is important to know the flow condensation heat transfer coefficients (HTCs) of refrigerants.

\subsection{Principle of Condensation:}

This principle explains what happens when a hot vapor stream contacts a cooler surface. Heat will be transferred from the hot surface to the cooler surface. Lowering the temperature reduces the average kinetic energy of the gas. Also, the volume that these vapors occupy is the reduced space. Ultimately, the gas molecules are crowded together so that the attractive forces between the molecules cause them to condense to a liquid (Saturday et al, 2017).

Two conditions that would aid condensation are: Low temperature and High pressure. Condensation of a gas would depend on its physical or chemical properties. Condensation may occur in variety of modes. The modes are described as follows:

Film wise Condensation: Here, the condensed liquid forms a continuous liquid film on the heat transfer surface. The surface can be a flat plate or the outside or inside of a round tube. In design of condensers, it is usually assumed that the condensation will be in the film wise mode.

Drop wise Condensation: If the heat transfer surface has poor wetting characteristic, the condenser may be formed as droplets, which are initially stationary on the surface but which ultimately grow large enough to move across the surface under the influence of gravity or vapor shear.

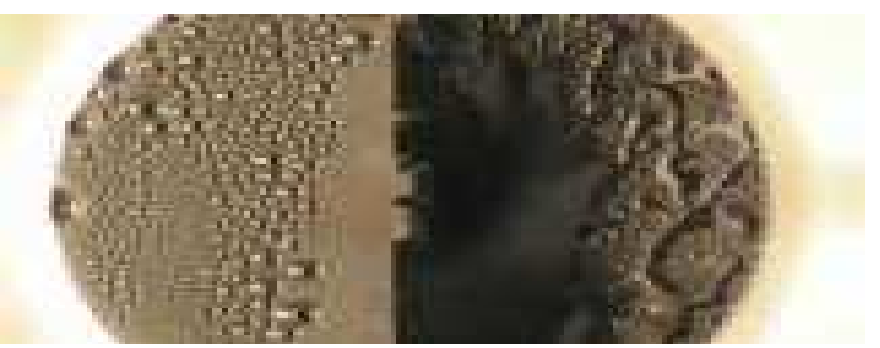

Figure 9: Filmwise and Dropwise Condensation (Gaurav, 2017)

\section{DESIGN}

Design of condenser is done by using various correlations to calculate the heat transfer coefficient from air side and refrigerant side. Propane is used as refrigerant because its thermo physical properties are better as compared to recently used refrigerant in automobile condenser. It is an eco-friendly natural refrigerant which has very low Global Warming Potential and zero Ozone Depletion Potential and has no direct impact on the greenhouse effect. Heat transfer of finned tube air cooled condenser is given by:

$\mathrm{Q}=\mathrm{U}_{\mathrm{t}} \mathrm{A}_{\mathrm{t}} \mathrm{LMTD}$

\section{Design Criteria}

\subsection{Water Cooled Condensers}

The design of a steam condenser depends on circumstances peculiar to the power plant in which it is to be installed. The temperature and availability of cooling water, pressure drop restrictions, purity of cooling water 
and a host of other parameters influence the choice of design parameters.

\subsubsection{Cooling water velocity}

Cooling water velocity to be used depends on the material selected and is based on the considerations of erosion and fouling. Since the principal barrier to heat transfer is the heat transfer coefficient on the water side, there is a strong incentive to increase the cooling water velocity. A high velocity results in erosion, wear and high pressure drop while low velocity promotes deposit accumulation and corrosion. The heat exchange institute recommends a velocity ranging from 5 to $8 \mathrm{fps}$ for a good compromise between heat transfers and pumping power requirements.

\subsubsection{Overall heat transfer coefficient}

The overall heat transfer coefficient is primarily a function of cooling water velocity, purity of water and temperature of cooling water. An increase in its value will decrease the size of the condenser required.

\subsubsection{Tube parameters}

The tube material to be used depends on the type of water and environment. A smaller diameter tube and thickness gives lower surface area requirements as well as lower pressure drops for the same velocity compared to a larger sized tube or larger thickness. This is because, for a fully developed flow the Nusselt number is constant. So, as the diameter of the tube increases, the heat transfer coefficient decreases to maintain the Nusselt number as a constant. Therefore, the surface area required for heat transfer increases. However, higher water velocities cannot be used in a small tube. Hence, based on the above considerations a decision may be taken (Parikshit and Choudhari, 2016).

\subsubsection{Temperature of cooling water}

A lower temperature of cooling water allows the turbine to be operated at lower pressures due to which a higher turbine output may be obtained and also, the surface area requirement of the condenser is decreased. A very low temperature may lead to subcooling. In such a case, the temperature rise in the condenser can be restricted.

\subsubsection{Pressure drop}

The pressure drop inside the tubes should be maintained small so as to reduce the pumping power required. Generally accepted value ranges from 2 to 7 psi.

\subsection{Air Cooled Condensers}

The design of an air cooled condenser primarily depends on the dry bulb temperature at the plant location, air velocity, type of tube arrangement, pitch and space restrictions.

\subsubsection{Dry bulb temperature}


Since the cooling medium for steam is air, a higher ambient temperature results in a lower heat transfer coefficient and hence a larger size condenser is required. At lower temperatures a smaller condenser is sufficient. An air cooled condenser is generally designed for a temperature that is 2 to $5 \%$ higher than the highest ambient temperature at that location.

\subsubsection{Air velocity}

A higher air velocity implies a larger heat transfer coefficient and hence a smaller condenser size. But we need to supply more fan power in such conditions and the pressure drop across the tubes increases. So a compromise must be made between fan power requirements and overall heat transfer coefficient.

\subsubsection{Tube arrangement:}

The tubes may be arranged in an inline or staggered fashion as shown in Fig.9 below. The inline tubes tend to give a lower pressure drop and poorer heat transfer because the flow tends to be channeled into high velocity regions in the center of the lanes between the tube rows. Staggered tubes on the other hand, produce good mixing of the flow over the tube banks but give a higher pressure drop.
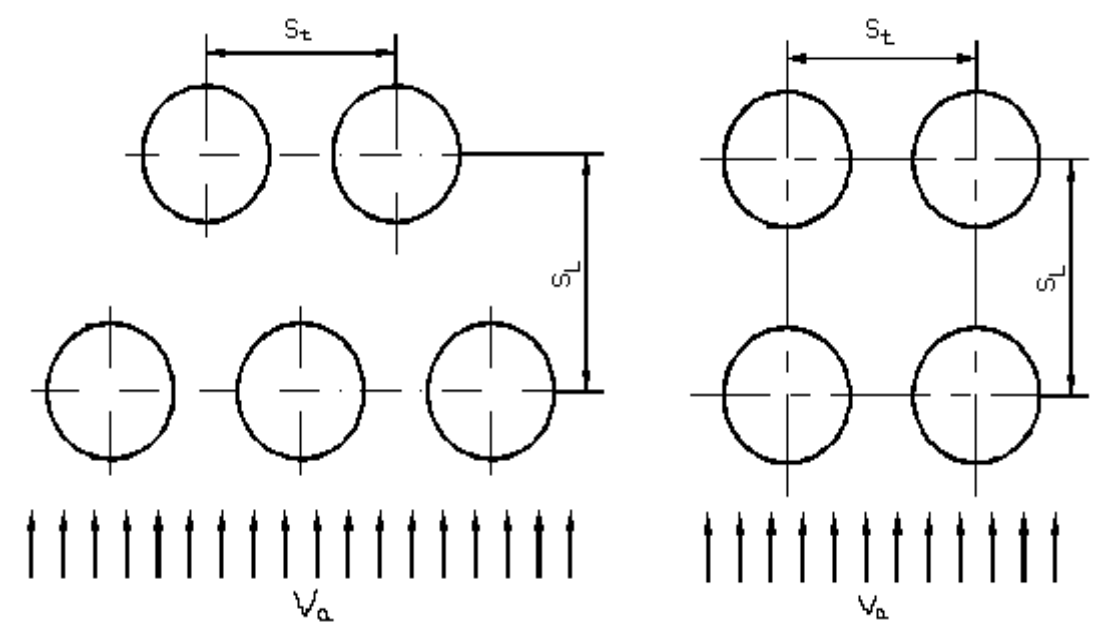

Figure 10: Showing staggered and inline arrangement (Murti, 2015)

\subsubsection{Pitch}

As the distance between the successive tubes increases the pressure drop on the fin side decreases due to less obstruction. But a higher pitch occupies more space. So, a balance between space restrictions and pressure drop must be made.

\subsection{Design Procedure for Water Cooled Condenser}

In the design of condensers calculation of heat transfer co-efficient are the most significant and should be determined with reasonable accuracy. When the cooling medium has a reasonably high heat transfer co-efficient such as water, the heat transfer co-efficient inside and outside the tubes compares well. A significant error in estimating this would affect the overall size of the equipment. The heat exchanger is designed to heat or cool a 
steam for which the flow rate, an acceptable pressure drop, and inlet and outlet temperatures are defined. The LMTD will depend only on the flow configuration. Practical considerations such as fabrication and maintenance determine the tube diameter and geometric arrangement. Once the geometric pattern is fixed, the relations between the fluid mass flow rate outside the tubes and both the pressure drop and heat transfer coefficient are then defined.

\subsubsection{Design calculation assuptions:}

1. Assuming shell and tube heat exchanger

2. No. of tube passes, $\mathrm{n}=1$

3. Velocity of cooling water, $V=5.5 \mathrm{fps}$ ( 5 to $10 \mathrm{fps}$ )

4. Condenser purity factor for water with chemical treatment, $\beta=0.8$

5. Tube size 0.5 inch, 18 BWG.

The steps for designing a water cooled condenser are as follows:

Step 1: Find the heat duty of condenser

$\mathrm{Q}=$ ws $(\mathrm{x}) \mathrm{hfg}$

Step 2: Find mass flow rate of cooling water

$\mathrm{wc}=\mathrm{Q} / \mathrm{Cp}($ two-twi $)$

Step 3: Find overall heat transfer co-efficient

$\mathrm{U}=4070.5 \beta[0.51 \mathrm{~V}] \mathrm{x}[1-(0.42 \sqrt{ } \beta(35-\mathrm{twi}) 2 / 1000)]$

Step 4: Calculation of cooling surface area

$\mathrm{A}=\mathrm{wcln}[(\mathrm{T}-\mathrm{twi}) /(\mathrm{T}-\mathrm{two})][0.022 / \mathrm{di}](\mathrm{x} / 4) /(\mathrm{U} \Phi)$

Step 5: Find number of tubes. This is found using the continuity equation.

$\mathrm{N}=(4 \mathrm{wc}) /(\pi \mathrm{di} 2 \rho \mathrm{v})$

Step 6: Find the approximate length of tube

$\left.\mathrm{L}=((900 \mathrm{v} \rho) / \mathrm{U})[\ln ((\mathrm{T}-\mathrm{twi}) /(\mathrm{T}-\mathrm{two}))]((\mathrm{di}) 2 / \mathrm{nd})\left((0.022 / \mathrm{di})^{(\mathrm{x} / 4) /} \Phi\right)\right)$

Step 7: Find the accurate length of tube. This is based on the heat transfer area required.

$\mathrm{N}=\mathrm{A} / \pi \mathrm{dL}$

Initially assume length of the tube $\mathrm{L}$ as obtained in the previous step. Then iterate by varying $\mathrm{L}$ until the number of tubes $\mathrm{N}$ equals that obtained in Step 5. This value of $\mathrm{L}$ gives the accurate length of the tube. 
Step 8: Determination of shell diameter

$\operatorname{Ds}=\mathrm{d}(\sqrt{ }(\mathrm{N} / \mathrm{k}))$ The occupancy factor $\mathrm{k}$ varies from 0.24 to 0.31

Step 9: Determination of pumping power

Ppump = Qhp / (102 ๆp )

Step 10: Determination of cooling tower fan power

Pfan $=$ Qhf $/(102 \eta f)$

\subsection{Performance Evaluation}

Certain parameters were varied in order to calculate the coefficient of performance of the refrigeration and air conditioning system. For this investigation, the optimization was done by varying the geometric design parameters specific to the condenser coil. As part of the optimization process, comparisons were made between the seasonal performances of air-conditioning systems with condensers of various geometric configurations. There are large numbers of condenser coil geometric design parameters that could be varied in order to optimize the seasonal performance of an air-conditioning system. These parameters include the tube diameter, the tube spacing, the number of refrigerant parallel flow circuits, and the number of tubes per refrigerant parallel flow circuit, and the fin spacing or pitch.

\section{RESULTS AND DISCUSSIONS}

Experimental evaluation of a condenser and its effect on refrigeration and air conditioning cycle.

Table 1: When The Compressor Is On

\begin{tabular}{|c|c|c|c|c|c|c|c|c|c|c|}
\hline $\mathbf{L P}$ & $\mathbf{H P}(\mathbf{p s i})$ & $\mathbf{T}_{\mathbf{1}}{ }^{\mathbf{C}} \mathbf{C}$ & $\mathbf{T}_{\mathbf{2}}{ }^{\mathbf{C}} \mathbf{C}$ & $\mathbf{T}_{\mathbf{3}} \mathbf{}^{\mathbf{0}} \mathbf{C}$ & $\mathbf{T}_{\mathbf{4}}{ }^{\mathbf{0}} \mathbf{C}$ & $\mathbf{T}_{\mathbf{5}}{ }^{\mathbf{}} \mathbf{C}$ & $\mathbf{T}_{\mathbf{6}}{ }^{\mathbf{0}} \mathbf{C}$ & $\mathbf{C M}$ & $\mathbf{L 1}$ & $\mathbf{E} 1$ \\
\hline $35(\mathrm{psi})$ & $145(\mathrm{psi})$ & 13 & 44 & 37 & 30 & 20 & 24 & ON & OFF & LO \\
\hline $2.41(\mathrm{bar})$ & $10.0(\mathrm{bar})$ & & & & & & & & & \\
\hline
\end{tabular}

Condensation is high when the compressor is on. Condenser inlet temperature $\mathrm{T}_{3}{ }^{0} \mathrm{C}$ have a higher value than the outlet $\mathrm{T}_{4}{ }^{0} \mathrm{C}$.

Table 2: When Compressor Is Off $\left({ }^{0} \mathrm{c}\right)$

\begin{tabular}{|c|c|c|c|c|c|c|c|c|c|c|}
\hline $\mathbf{L P}(\mathbf{P s i})$ & $\mathbf{H P}$ & $\mathbf{T}_{\mathbf{1}}{ }^{\mathbf{0}} \mathbf{F}$ & $\mathbf{T}_{\mathbf{2}}{ }^{\mathbf{0}} \mathbf{F}$ & $\mathbf{T}_{3}{ }^{0} \mathbf{F}$ & $\mathbf{T}_{\mathbf{4}}{ }^{\mathbf{0}} \mathbf{F}$ & $\mathbf{T}_{5}{ }^{0} \mathbf{F}$ & $\mathbf{T}_{\mathbf{6}}{ }^{\mathbf{0}} \mathbf{F}$ & $\mathbf{C M}$ & $\mathbf{L I}$ & $\mathbf{E} 1$ \\
\hline 33 & 123 & 23 & 43 & 34 & 31 & 16 & 19 & OFF & OFF & LO \\
\hline
\end{tabular}

Condensation is not too noticed when the compressor goes off. Condenser inlet temperature $\mathrm{T}_{3}{ }^{0} \mathrm{C}$ have a higher value than the outlet $\mathrm{T}_{4}{ }^{0} \mathrm{C}$

Table 3: When Evaporator Fan (E1) Changes To High $\left({ }^{0} \mathrm{c}\right)$

\begin{tabular}{|c|c|c|c|c|c|c|c|c|c|c|}
\hline $\mathbf{L P}$ & $\mathbf{H P}$ & $\mathbf{T}_{\mathbf{1}}{ }^{\mathbf{}} \mathbf{C}$ & $\mathbf{T}_{2}{ }^{\mathbf{0}} \mathbf{C}$ & $\mathbf{T}_{\mathbf{3}}{ }^{\mathbf{0}} \mathbf{C}$ & $\mathbf{T}_{\mathbf{4}}{ }^{\mathbf{0}} \mathbf{C}$ & $\mathbf{T}_{\mathbf{5}}{ }^{\mathbf{0}} \mathbf{C}$ & $\mathbf{T}_{\mathbf{6}}{ }^{\mathbf{}} \mathbf{C}$ & $\mathbf{C M}$ & $\mathbf{L I}$ & $\mathbf{E} 1$ \\
\hline 18 & 133 & 22 & 43 & 36 & 31 & 19 & 22 & ON & OFF & HI \\
\hline
\end{tabular}

Condensation is not too noticed when the evaporator fan speed is increased. Condenser inlet temperature $\mathrm{T}_{3}{ }^{0} \mathrm{C}$ have a higher value than the outlet $\mathrm{T}_{4}{ }^{0} \mathrm{C}$ 
Table 4: When Evaporator Fan (E1) Changes To Low ( $\left.{ }^{0} \mathrm{c}\right)$

\begin{tabular}{|c|c|c|c|c|c|c|c|c|c|c|}
\hline $\mathbf{L P}(\mathbf{p s i})$ & $\mathbf{H P}(\mathbf{P s i})$ & $\mathbf{T}_{\mathbf{1}}{ }^{\mathbf{0}} \mathbf{C}$ & $\mathbf{T}_{\mathbf{2}}{ }^{\mathbf{0}} \mathbf{C}$ & $\mathbf{T}_{\mathbf{3}}{ }^{\mathbf{0}} \mathbf{C}$ & $\mathbf{T}_{\mathbf{4}}{ }^{\mathbf{0}} \mathbf{C}$ & $\mathbf{T}_{\mathbf{5}}{ }^{\mathbf{0}} \mathbf{C}$ & $\mathbf{T}_{\mathbf{6}}{ }^{\mathbf{0}} \mathbf{C}$ & $\mathbf{C M}$ & $\mathbf{L I}$ & $\mathbf{E} 1$ \\
\hline 16 & 129 & 24 & 46 & 36 & 30 & 17 & 22 & $\mathrm{ON}$ & $\mathrm{ON}$ & $\mathrm{LO}$ \\
\hline
\end{tabular}

Condensation is high when the evaporator fan speed is reduced. Condenser inlet temperature $\mathrm{T}_{3}{ }^{0} \mathrm{C}$ have a higher value than the outlet $\mathrm{T}_{4}{ }^{0} \mathrm{C}$.

Table 5: When Evaporator Fan (E1) Changes To High ( $\left.{ }^{0} \mathrm{c}\right)$

\begin{tabular}{|c|c|c|c|c|c|c|c|c|c|c|}
\hline $\mathbf{L P}(\mathbf{p s i})$ & $\mathbf{H P}(\mathbf{P s i})$ & $\mathbf{T}_{\mathbf{1}} \mathbf{0}^{\mathbf{C}}$ & $\mathbf{T}_{\mathbf{2}}{ }^{\mathbf{0}} \mathbf{C}$ & $\mathbf{T}_{\mathbf{3}}{ }^{\mathbf{}} \mathbf{C}$ & $\mathbf{T}_{\mathbf{4}}{ }^{\mathbf{}} \mathbf{C}$ & $\mathbf{T}_{\mathbf{5}}{ }^{\mathbf{}} \mathbf{C}$ & $\mathbf{T}_{\mathbf{6}}{ }^{\mathbf{}} \mathbf{C}$ & $\mathbf{C M}$ & $\mathbf{L} 1$ & $\mathbf{E} 1$ \\
\hline 16 & 129 & 24 & 46 & 36 & 30 & 18 & 21 & ON & ON & HI \\
\hline
\end{tabular}

With thermal load L1, Condensation is high when the evaporator fan speed is increased. Condenser inlet temperature $\mathrm{T}_{3}{ }^{0} \mathrm{C}$ has a higher value than the outlet $\mathrm{T}_{4}{ }^{0} \mathrm{C}$.

Table 6: When Evaporator Fan (E1) Changes To Low ( $\left.{ }^{0} \mathrm{c}\right)$

\begin{tabular}{|c|c|c|c|c|c|c|c|c|c|c|}
\hline $\mathbf{L P}(\mathbf{p s i})$ & $\mathbf{H P}(\mathbf{P s i})$ & $\mathbf{T}_{\mathbf{1}}{ }^{\mathbf{0}} \mathbf{C}$ & $\mathbf{T}_{\mathbf{2}}{ }^{\mathbf{}} \mathbf{C}$ & $\mathbf{T}_{\mathbf{3}}{ }^{\mathbf{C}} \mathbf{C}$ & $\mathbf{T}_{\mathbf{4}}{ }^{\mathbf{0}} \mathbf{C}$ & $\mathbf{T}_{\mathbf{5}}{ }^{\mathbf{0}} \mathbf{C}$ & $\mathbf{T}_{\mathbf{6}}{ }^{\mathbf{C}} \mathbf{C}$ & $\mathbf{C M}$ & $\mathbf{L I}$ & $\mathbf{E} 1$ \\
\hline 18 & 129 & 24 & 47 & 36 & 30 & 18 & 22 & $\mathrm{ON}$ & $\mathrm{ON}$ & $\mathrm{LO}$ \\
\hline
\end{tabular}

With thermal load L1, Condensation is high. Condenser inlet temperature $\mathrm{T}_{3}{ }^{0} \mathrm{C}$ have a higher value than the outlet $\mathrm{T}_{4}{ }^{0} \mathrm{C}$.

Table 7: When Compressor Goes Off

\begin{tabular}{|c|c|c|c|c|c|c|c|c|c|c|}
\hline $\mathbf{L P}$ & $\mathbf{H P}$ & $\mathbf{T}_{\mathbf{1}}$ & $\mathbf{T}_{\mathbf{2}}$ & $\mathbf{T}_{\mathbf{3}}$ & $\mathbf{T}_{\mathbf{4}}$ & $\mathbf{T}_{\mathbf{5}}$ & $\mathbf{T}_{\mathbf{6}}$ & $\mathbf{C M}$ & $\mathbf{L I}$ & $\mathbf{E 1}$ \\
\hline 18 & 125 & 77 & 120 & 96 & 86 & 57 & 64 & OFF & OFF & LO \\
\hline
\end{tabular}

System said to be on relaxation stage. This enables the compressor to function effectively.

Table 8: Pressure and Temperature Values at 1minutes Interval

\begin{tabular}{|c|c|c|c|c|c|c|c|c|}
\hline TIME(Min) & LP(Psi) & HP(Psi) & $\mathrm{T}_{1}^{\mathrm{O}} \mathrm{C}$ & $\mathrm{T}_{2}{ }^{\mathrm{O}} \mathrm{C}$ & $\mathrm{T}_{3}{ }^{0} \mathrm{C}$ & $\mathrm{T}_{4}{ }^{0} \mathrm{C}$ & $\mathrm{T}_{5}^{0} \mathrm{C}$ & $\mathrm{T}_{6}{ }^{0} \mathrm{C}$ \\
\hline 1 & 86 & 117 & 33 & 35 & 33 & 31 & 26 & 28 \\
\hline 2 & 16 & 133 & 30 & 47 & 36 & 31 & 23 & 26 \\
\hline 3 & 13 & 129 & 28 & 49 & 36 & 31 & 20 & 24 \\
\hline 4 & 8 & 129 & 27 & 50 & 36 & 31 & 19 & 23 \\
\hline 5 & 13 & 129 & 27 & 50 & 36 & 31 & 19 & 23 \\
\hline 6 & 13 & 129 & 27 & 50 & 36 & 31 & 18 & 23 \\
\hline 7 & 8 & 129 & 27 & 50 & 36 & 31 & 18 & 22 \\
\hline
\end{tabular}

condenser temperatures

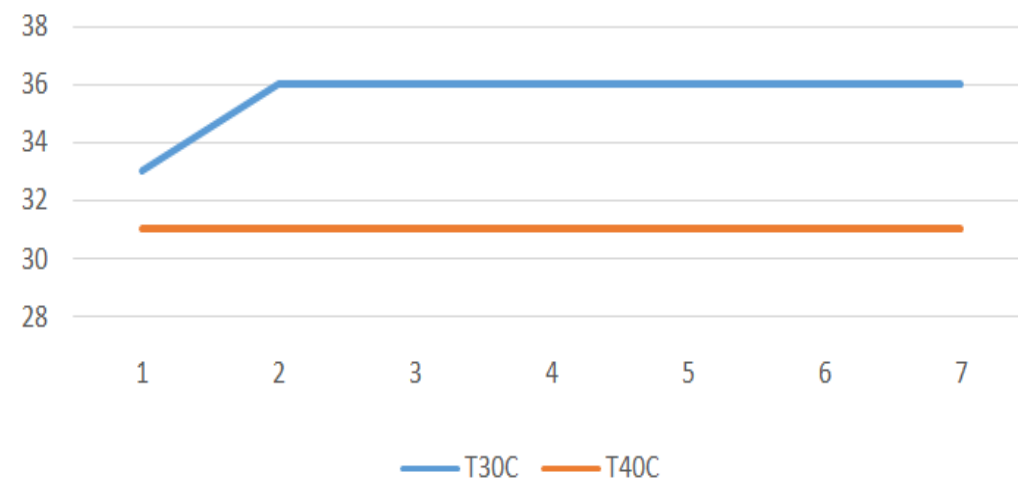

Figure 11: Condenser Temperatures. 
Table 9: System Justification

\begin{tabular}{|c|c|c|c|c|c|c|c|c|c|c|c|c|}
\hline $\mathbf{S} / \mathbf{N}$ & $\mathbf{C M}$ & $\mathbf{E}_{\mathbf{1}}$ & $\mathbf{S}_{\mathbf{1}}{ }^{\mathbf{F}}$ & $\mathbf{D}_{\mathbf{1}}{ }^{\mathbf{0}} \mathbf{F}$ & $\mathbf{L P}(\mathbf{p s i})$ & $\mathbf{H P}(\mathbf{p s i})$ & $\mathbf{T}_{\mathbf{1}}{ }^{\mathbf{F}} \mathbf{F}$ & $\mathbf{T}_{\mathbf{2}}{ }^{\mathbf{0}} \mathbf{F}$ & $\mathbf{T}_{\mathbf{3}} \mathbf{}_{\mathbf{F}}$ & $\mathbf{T}_{\mathbf{4}}{ }^{\mathbf{F}} \mathbf{F}$ & $\mathbf{T}_{\mathbf{5}}{ }^{\mathbf{0}} \mathbf{F}$ & $\mathbf{T}_{\mathbf{6}}{ }^{\mathbf{0}} \mathbf{F}$ \\
\hline 1 & ON & LO & 20 & 5 & 28 & 135 & 22 & 45 & 38 & 32 & 15 & 19 \\
\hline 2 & OFF & LO & 20 & 5 & 79 & 122 & 27 & 36 & 33 & 33 & 24 & 25 \\
\hline 3 & ON & HI & 20 & 5 & 30 & 141 & 24 & 46 & 38 & 32 & 17 & 19 \\
\hline 4 & OFF & HI & 20 & 5 & 79 & 128 & 28 & 40 & 30 & 33 & 26 & 25 \\
\hline
\end{tabular}

\section{OPERATIONAL PRINCIPLES AND MATERIALS}

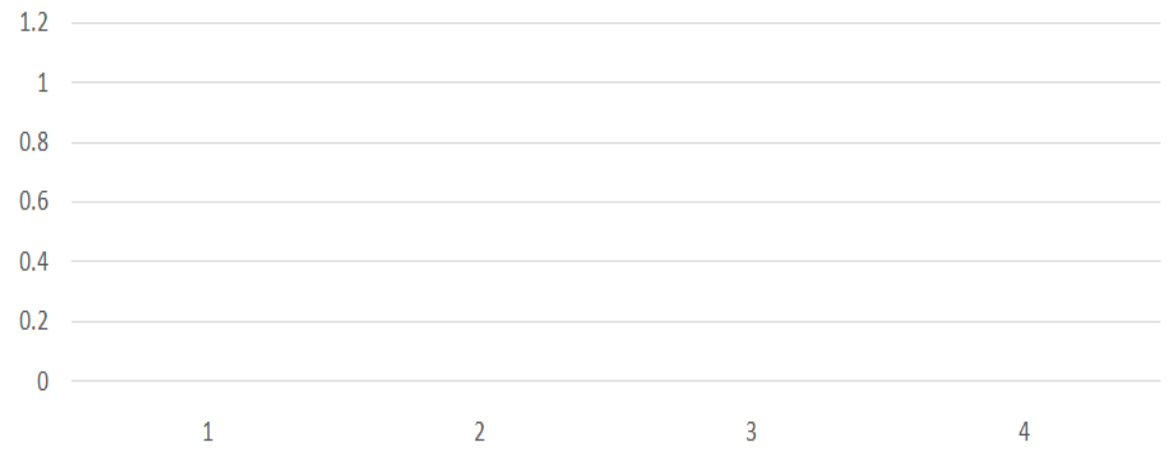

Figure 12: System Justification.

The Behavior Shows That the Condensation Occurred and There Is Need to Further Sub Cool the System

Table 10: Cooling System

\begin{tabular}{|c|c|c|c|c|c|c|c|c|c|c|c|c|c|c|c|}
\hline $\mathbf{S} / \mathbf{N}$ & $\mathbf{S}_{1}{ }^{0} \mathbf{F}$ & $\mathbf{D}_{1}{ }^{0} \mathbf{F}$ & $\mathbf{T}_{5}{ }^{0} \mathbf{F}$ & $\mathbf{T}_{6}^{0} \mathbf{F}$ & $V_{5}$ & $\mathbf{S}_{2}{ }^{0} \mathbf{F}$ & $\mathbf{D}_{2}{ }^{0} \mathbf{F}$ & $\mathbf{T}_{7}^{0} \mathbf{F}$ & $\mathbf{T}_{8}{ }^{0} \mathbf{F}$ & $\mathrm{V}_{6}^{0} \mathrm{~F}$ & LP(Psi) & HP(Psi) & CM & OF & $\mathbf{t}($ Mins $)$ \\
\hline 1 & 64 & 9 & 66 & 69 & $\mathrm{ON}$ & 68 & 9 & 69 & 75 & ON & 42 & 135 & $\mathrm{ON}$ & ON & $2: 30$ \\
\hline 2 & 64 & 9 & 60 & 66 & $\mathrm{ON}$ & 68 & 9 & 64 & 71 & $\mathrm{ON}$ & 37 & 131 & $\mathrm{ON}$ & ON & 5:00 \\
\hline 3 & 64 & 9 & 59 & 64 & OFF & 68 & 9 & 62 & 69 & ON & 37 & 131 & $\mathrm{ON}$ & ON & $7: 50$ \\
\hline 4 & 64 & 9 & 66 & 66 & OFF & 68 & 9 & 60 & 66 & OFF & 35 & 115 & OF & OF & $10: 00$ \\
\hline 5 & 64 & 9 & 73 & 73 & ON & 68 & 9 & 71 & 71 & OFF & 52 & 109 & On & On & $12: 30$ \\
\hline 6 & 64 & 9 & 66 & 69 & ON & 68 & 9 & 75 & 75 & $\mathrm{ON}$ & 47 & 133 & ON & ON & $15: 00$ \\
\hline 7 & 64 & 9 & 62 & 66 & ON & 68 & 9 & 71 & 71 & ON & 42 & 133 & ON & ON & $17: 30$ \\
\hline 8 & 64 & 9 & 59 & 62 & OFF & 68 & 9 & 68 & 68 & ON & 35 & 131 & ON & ON & 20:00 \\
\hline
\end{tabular}




\section{COOLING SYSTEM}

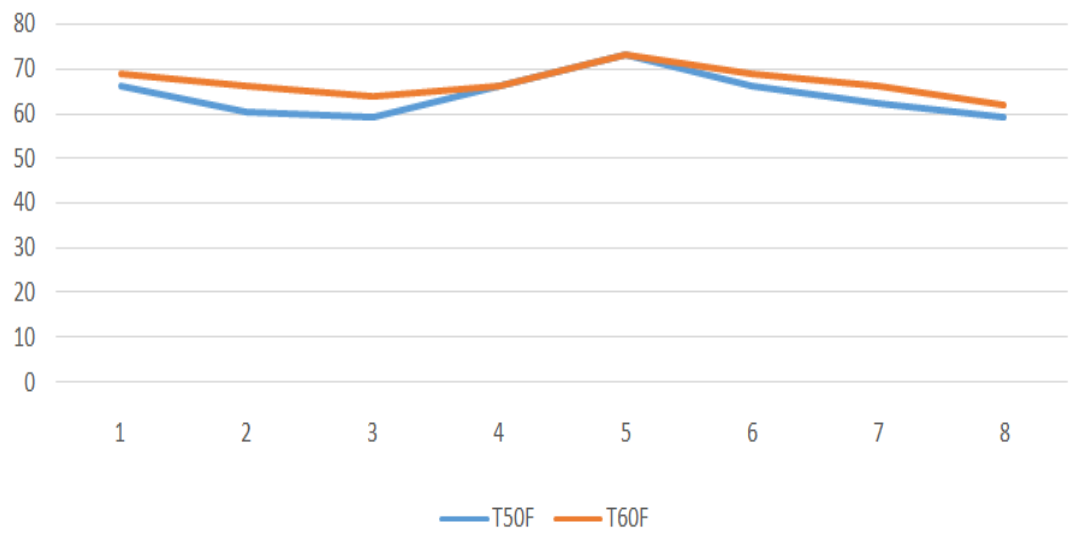

Figure 13: Cooling System chart

Condenser was designed using solid works 2016 and the design imported to ansys fluent. The performance of the condensers are depicted from the figures 14,15 and 16 :

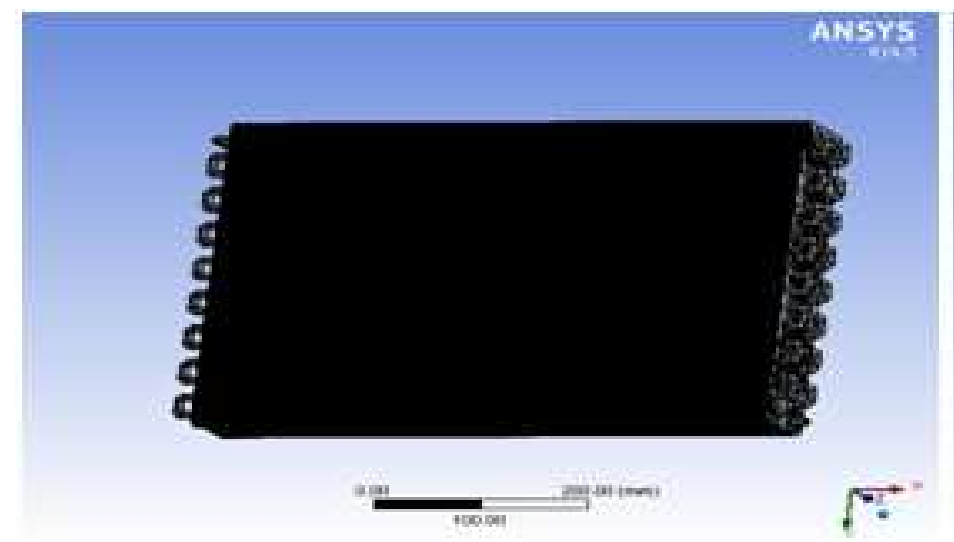

Figure 14:Meshing.

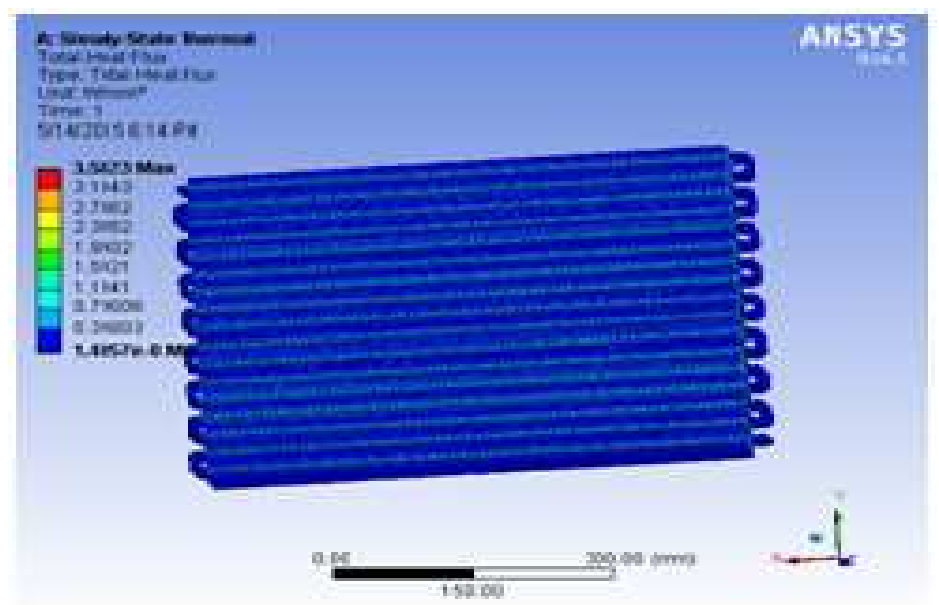

Figure 15: Directional Heat Flux. 


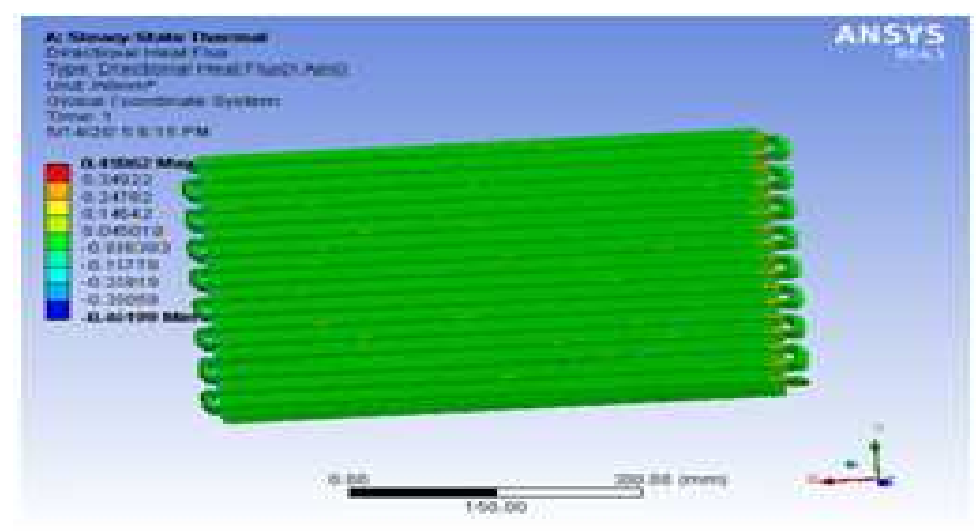

Figure 16: Total Heat Flux

R134a refrigerant performed seamlessly when subjected to the design. The heat flux along the copper tubes seems to be high.

\section{CONCLUSION}

As already mentioned, condenser is an important component of any refrigeration system. In a typical refrigerant condenser, the refrigerant enters the condenser in a superheated state. It is first de-superheated and then condensed by rejecting heat to an external medium. The refrigerant may leave the condenser as a saturated or a sub-cooled liquid, depending upon the temperature of the external medium and design of the condenser.

From the analysis results, the heat transfer rate is more when refrigerant R134a is used since heat flux is more. When compared, the results for tube material between Copper and Aluminum, using Copper is better. But the disadvantage of using Copper is its weight, so aluminum alloy 1100 can be an alternative. When compared the results for fin material between Aluminum alloy 1100 and 1050, using Aluminum alloy 1050 is better. Heat transfer analysis is done on the condenser to evaluate the material and refrigerant. The materials considered for tubes are Copper and Aluminum alloy 1100 and for fins are 1050 and 1100. The refrigerants used is R134a.

3D modeling is done in solid works and analysis is done in Ansys. From the analysis results, the heat transfer rate is more when refrigerant $\mathrm{R} 134 \mathrm{a}$ is used since heat flux is more.

\section{REFERENCES}

1. Anil S. Patil,Atul A Patil,V.H.Patil.Design and Development of Water Cooled Condenser for Domestic Refrigerator. Pratibha: International Journal of Science, Spirituality, Business and Technology (IJSSBT), Vol. 4, No. 2, May 2016 ISSN (Print) 2277_7261.

2. Ali HussainTarrad\& Ali Farhan Al-Tameemi. Experimental and Numerical Model for Thermal Design of Air Cooled Condenser. Global Journal of Researches in Engineering: a Mechanical and Mechanics Engineering Volume 15 Issue 3Version 1.0 Year 2015 Type: Double Blind Peer Reviewed International Research Journal Publisher: Global Journals Inc. (USA) Online ISSN: 22494596 Print ISSN: 09755861. 
3. Sharma, Ankush, and Jagdev Singh. "Experimental investigation of refrigerant flow rate with spirally coiled adiabatic capillary tube in vapour compression refrigeration cycle using eco friendly refrigerant." International Journal of Mechanical and Production Engineering Research and Development 3 (2013): p8594.

4. A D Parekh, and P R Tailor. Thermal Design of Condenser Using Ecofriendly Refrigerants R404A-R508B for Cascade Refrigeration System. 4th International Conference on Mechanical, Production and Automobile Engineering (ICMPAE'2013) Oct. 6-7, 2013 Dubai (UAE).

5. Yusuf Ali KARA. A Simplified Three-Zone Model for Designing Shell-And-Tube Refrigerant Condensers. Ist BilimiveTekniğiDergisi, 34, 1, 9-18, 2014. J. of Thermal Science and Technology (02014 TIBTD Printed in Turkey ISSN 13003615.

6. Kumar, V. Ashok, and N. Sathishkumar. "Effect of fin geometry for various tubes shape using CFD simulation on multi-channel heat exchanger in mobile air conditioning (MAC)." International Journal of Mechanical and Production Engineering Research and Development (IJMPERD) 8 (2018): 2632.

7. E. G. Saturday, C. E. Chidebe, U. Nwaiwu. Computer Aided Comparative Analysis of the Effects of Superheating and Subcooling on the Performance of R134a and R717 in Simple Vapour Compression Systems. International Journal of Computer Applications (0975 - 8887) Volume 157 - No 5, January 2017.

8. Sravanthi, P., and K. Radha Rani. "Transient Stability improvement of SCIG Based Wind farm With STATCOM." Journal of Electrical and Electronics Engineering Research (IJEEER) 4.2 (2014).

9. Zhaoying Zhang and JianguoYang.The Effect of Face-Air Velocity Distribution on Heat Transfer Performance of Air-Cooled Condensers.International Journal of Heat and Technology Vol.33, No.1, 2015.

10. R.HussainVali ,P.Yagnasri, S.Naresh Kumar Reddy. Performance Analysis Of Ver System With Varying The Diameters Of Helical Condenser Coil By Using R-134a Refrigerant. Ijesrt International Journal of Engineering Sciences \& Research Technology.Issn: 2277-9655 (I2or), Publication Impact Factor: 3.785.

11. Benziger, B., P. Anu Nair, and P. Balakrishnan. "Review paper on thermoelectric airconditioner using peltier modules." IJME 4.

12. N.Venkatesh and B B V Kishore, "Design and Analysis of AC Condenser for Improving Efficiency", International Journal for Modern Trends in Science and Technology, Vol. 03, Issue 09, September 2017, pp.-143148.

13. Mike Sinkevich,AlexanderBelokon. Application of Thermo-pur Manufacturing Technology to Air Cooled Condensers. TPT 2014-1 February 19, 2014.

14. Senthilkumar, P. "Environmental Effect Of Using Diesel On Waste Plastic Oil Fueled In Diesel Engine." International Journal of Mechanical Engineering (IJME) 7. 3, Apr - May 2018.

15. TV V S N Murti, P Sreenivas. Optimization of Parallel Condensing In Steam Power Plant. IOSR Journal of Mechanical and Civil Engineering (IOSR-JMCE) e-ISSN: 2278-1684,p-ISSN: 2320-334X, Volume 13, Issue 1 Ver. VI (Jan- Feb. 2015), PP 1520 www.iosrjournals.org.

16. GauravShukla. Mathematical Modeling and Simulation of Multi component Condenser for the condensation of Hydrocarbon vapour mixture using MATLAB. (C) May 2017 IJSDR | Volume 2, Issue 5.

17. Parikshit A. Ladke1, C.S. Choudhari2. International Research Journal of Engineering and Technology (IRJET) e-ISSN: 2395 0056 Volume: 03 Issue: 06 | June-2016 www.irjet.net p-ISSN: 23950072. 
18. NadadariBheemesh, N. Venkateswarlu. Design and Heat Transfer Analysis of AC Condenser for Different Materials. International Journal \& Magazine of Engineering, Technology, Management and Research. 